\title{
Improving marketing activities of small enterprises that produce building materials
}

\author{
Pavel Shikov ${ }^{1, *}$ and Yuri Shikov ${ }^{1}$ \\ ${ }^{1}$ St. Petersburg State University industrial technologies and design, ul. Bolshaya Morskaya, 18, \\ 191186, St. Petersburg, Russia
}

\begin{abstract}
The article examines the problems of improving the marketing activities of small enterprises that produce construction materials. We propose concrete measures based on the experience of the most advanced enterprises that implement innovations and modern information technologies. The most important of them are a deep marketing analysis of the market situation, promotion of their products and services on the Internet, cooperation with large and medium-sized businesses, the introduction of modern technologies into production and the creation of virtual enterprises. At present, competent marketing and sales policy is one of the main factors for increasing competitiveness. Marketing activities can be tailored to any environment and goods. The marketing policy depends on the market share, market development, competitors' actions, consumer influence and industrial enterprise goals.
\end{abstract}

\section{Introduction}

In order to achieve the maximum level of competitiveness, the company should realize all opportunities to increase the efficiency of the enterprise in all areas. With only few advantages implemented, the company cannot achieve the maximum growth in the market.

Many researchers believe that in order to achieve positive results for small businesses it is vital to create an innovative product or implement innovative business management techniques. "Another contemporary concept of management used by innovative companies is management of change. This concept refers to facilitating the fast implementation of any changes/innovations through the identification of internal stakeholders, such as pioneers of change, change agents, and opportunists (malcontents), and exerting influence on them» [1].

There are several ways to improve sales activities and increase the efficiency of small enterprises that produce construction materials:

- Market analysis.

- Analysis of competitors.

- Analysis of consumer demand.

- Expansion of sales channels.

${ }^{*}$ Corresponding author: pavel.shikov@mail.ru 
- Introduction of innovations.

- Training of personnel.

- Conducting advertising campaigns.

- Investing in new developments.

- Improving the quality and range of products (goods).

- Promotion of products and services on the Internet.

- Application of innovative management.

- Cooperation with large and medium-sized enterprises.

- Creation of virtual enterprises.

- And others.

Many small construction companies use a combined sales strategy, which combines:

- Direct marketing

- Indirect marketing

The first one is based on direct sales of goods to customers. Using this method is typical when products are sold through the company's call center.

In the second case of selling, the manufacturer of construction products uses the services of various independent intermediaries. Involvement of intermediaries is typical for the realization of building materials in other regions. The conducted studies of the market of building materials produced by small enterprises show that the largest share of $68 \%$ is attributed to indirect sales and $32 \%$ to the direct one (Fig. 1).

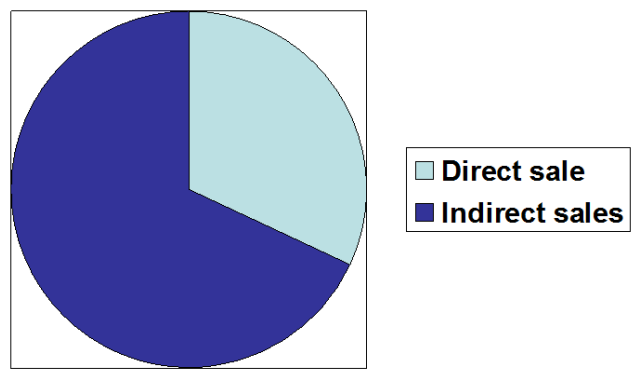

Fig. 1. Structure of buyers of construction products.

The price policy of the surveyed construction enterprises is oriented to ensuring the amount of profit necessary for conducting production and commercial activities. At the same time, the small enterprise sets following tasks when forming their price policy:

1. Ensuring optimal capacity utilization.

2. Increasing and maintainence the required sales volume.

3. Maintaining or increasing market share.

4. Attraction of new customers and retention of existing ones.

5. Reducing or maintaining the share of production costs.

6. And others.

These goals are realized through the establishment of lower prices, compared with those that could provide maximum profit to the enterprise.

\section{Materials and methods}

In order to increase sales, the company strives to achieve the highest quality of its own products and services. Therefore, this area is paid a lot of attention. To this end, construction companies create quality services that monitor compliance with the technological process, check the quality of raw materials coming to the enterprise. 
If we talk about the consumers of products of surveyed the small construction companies under study, they can be divided into three main categories:

- end customers - individuals who buy products for personal needs;

- construction companies, designers, architects who purchase products for the execution of works for the order;

- dealers specializing in distributing products.

Most of the clients in the first category are people with high and middle level of income. They are the owners of apartments, country cottages, houses for permanent residence.

The second group consists of companies that carry out the construction of housing and office space. In this case, the products of small construction enterprises are used for the construction and design of cottage settlements and country houses, as well as for creating original design solutions for prestigious urban housing.

The final purchasing group is represented by numerous dealers distributing products through their own sales systems. Sales of products and services of most of the small construction companies under surveillance take place through their own sales department and dealer network. The population accounts for about $32 \%$ of total sales. This is the most interesting and promising sales channel, as the sale of products is carried out at maximum prices without delays and often without discounts.

If we consider the long-term prospects for the development of small construction companies, the increase in sales volumes may continue mainly due to the development of new markets. And the potential of the local market is not exhausted to the end. This is evident due to the growth of the suburban real estate market and the construction materials market. Small construction companies pay great attention to maintaining the image of the brand and sales promotion. For these purposes, there are advertising departments at enterprises that promote products on the market. To increase the brand awareness for the end user, the following types of advertising are used:

- Mailing of letters.

- Outdoor advertising (banners along roads).

- Catalogs, flyers, booklets.

- Articles in weekly advertising and information publications related to suburban real estate and construction.

- Complex measures for the creation of the brand (diplomas, awards, certificates).

- Participation in industrial and specialized construction exhibitions.

- SMM (social media marketing).

- Digital marketing.

To attract private customers, one needs to think over additional services related to the purchase of finished goods in the online store and its delivery. An important aspect of successful operation of small enterprises engaged in the production of building materials is cooperation with large and medium-sized construction companies. Studies show that only this type of cooperation can ensure the sustainable management of small enterprises business. At the same time they must have a highly specialized, high quality products and competitive prices. Then small businesses will be able to successfully fit into the supply chain of large businesses. Подобные исследования проводились многими авторами в разных странах. «For the future action points, there are responsibility items for all the supply chain actors (e.g. HE, the SMEs and large companies). The gist of the findings for the future is to engage with the SMEs directly, to support them with necessary resources and incentivizing project delivery mechanisms, and to devise a continuous training plan going beyond the basics and specifically targeting the SMEs. Also, demonstrating the business case for LC through pilot LC projects, and effectively capturing and disseminating the LC knowledge seem necessary. Training and project governance related findings come to the fore» [2]. 
There are also very interesting and profound conclusions made by Valentinas Navickas and Asta Malakauskaite from Kaunas University of Technology «1.Companies tend to cooperate in order to achieve the effect of synergy in various fields of operation and improve their performance in the competitive environment. The forms of cooperation range from informal partnerships and alliances to net-works, clusters, associations, as well as complex technological platforms. 2. Clusters (clusterization) can be seen as a productivity and innovativeness improvement tool, while both innovativeness and productivity are greatly associated with growing competitiveness in national and global markets. Cluster policies can lead to economic and social development, generating new jobs and bringing people out of poverty. 3. SMEs that participate in clusters can benefit from specialized infrastructure, increased possibilities to penetrate new markets, qualified workforce, ability to meet the needs of clients, and cost reduction in manufacturing operations» [3].

\section{Results}

To achieve maximum efficiency, the time of placement of advertisements is taken into account. The peak of works on the improvement of the cottage area falls on the spring and autumn months, so advertising aimed at a private customer is located in early spring (March-May) and autumn (September-October). Advertising targeted at building organizations, is located from late May to September. This type of advertising can attract both private buyers and large construction companies.

\subsection{Development of recommendations for improving the marketing activities of small construction companies}

The conducted researches show the urgent necessity of constant perfection of marketing activity. This work should not be spontaneous and conducted periodically. To increase the effectiveness of marketing activities of small enterprises that produce building materials, it is expedient to apply the following development strategy:

1. Conduct a comprehensive marketing analysis of sales channels, assess the market capacity, analyze competitors and the demand of end-users in the prospective region of sales expansion and pricing policy.

2. Develop commercial proposals and negotiate with large and medium-sized chain stores.

3. Develop marketing activities for the retail network, as well as promotional activities in the media. Carry out a well-thought-out promotion of their products on the Internet.

4. Create your own online-store for the sale of manufactured building materials.

5. Participate in specialized exhibitions and promotions as part of urban or industrial programs.

6. Implement a new and effective promotion tool like SMM and digital marketing

As recommended measures to improve the marketing activities of small enterprises producing building materials, it is proposed:

- Increasing the efficiency of production by reducing costs, automation, robotics, increasing the number of shifts and loading the main technological equipment.

- Reduction, closure, outsourcing or re-profiling of inefficient or unprofitable sites.

- Improvement of the financial condition of the enterprise by reducing overhead costs, non-core costs, using cheaper raw materials and consumables.

- Improving the use of human resources by reducing the number of workers, improving their skills and effectiveness.

- The decrease in transport costs due to the optimization of logistics operations. 
- Improving the efficiency of working with clients, both existing and potential. Development of a system of discounts for partner firms and bonuses for representatives of customers who purchase products.

- Improving quality, expanding the range of products and services provided on the basis of the study of demand and conducted marketing research.

- Introduction of modern methods of organizing sales through the use of advanced Internet technologies, effective discount systems, flexible forms of payments, profitable commodity exchange transactions; granting of commercial and commodity credit, application of factoring.

- Rational use of production space and buildings.

To stimulate sales activity, it is necessary to create a modern website with the function of an online store.

The purpose of creating a website:

- the opportunity for potential buyers to familiarize themselves with products and services;

- the possibility of online ordering and payment;

- providing important information about current value, current balances in warehouses;

- the possibility of negotiations with a representative of the company on the website.

Customer benefits as obvious:

- Easy management system that does not require special training and expertise;

- quick orientation in assortment, assistance in finding the right product or service (by subject, name, value, etc.);

- easy viewing of information about discounts, bonuses, gifts and promotions;

- calculation of the total cost of the order;

- selection of products in the shopping cart;

- ordering on-line;

- simple formulation of delivery of products to the customer;

- maintenance of necessary contacts «seller-client».

Modern information technology and the launch of the website to a payback level is a feasible task for any small construction enterprise, and the developed measures to improve sales activity will allow increasing production volumes, increasing the profitability of companies and improving their financial condition.

At present, small construction companies should maximize the efficiency of all business processes at the enterprise by means of innovative management, flexibility and introduction of modern information technologies. "Construction firms need to be aware of the advantages of new management paradigms and practices. The analysis shows that SMEs in the construction sector have to internalize agile values into their business processes to reap the benefits of agile methods. It also reveals that existing practices show some kind of agile flavours» [4]. The most interesting and promising type of interaction with large and medium-sized enterprises of the industry are virtual enterprises that make it possible to quickly create and implement innovative products, quickly rebuild production for a particular project or order. «The modern production systems of virtual enterprise type become thus the fastest way to develop a new product and to select operational resources of SMEs. Modern business is agile, which means that it possess a rich informational content and has the organizational flexibility to adapt to any process. The competitive advantage is determined by the speed of arrival on the market, customer satisfaction and responsiveness to issues of social and environmental impact. Production and creation of new products are conducted simultaneously» [5].

The ability to integrate into complex production structures with other enterprises and organizations, the high quality of products and services, sectoral and technological 
specialization will allow small construction enterprises to successfully function and overcome obstacles «Virtual enterprise is a temporary alliance of companies which propose the resources and skills sharing in order to respond better and faster to the opportunities arising in the market. This production system fits the best on the structure of a modern industrial group achieved through a coalition of small and medium sized enterprises. This concept is supported by the new technologies and by the globalization phenomenon that begins to dominate the orientation of industrial development, functions and activities related to production being decentralized, distributed on large geographical areas. Virtual enterprise is materialized by selecting market conditions, skills and resources of various small and medium-sized enterprises, grouped in an alliance, in a consortium or in an industry group, focused on delivering a product or service, having the appearance of an integrated business [5].

Virtual enterprises are the best form of cooperation at the moment. Not to take this factor into account means to lose competitive advantages right now. Modernity, flexibility, advanced technologies in production and innovative management are the best guarantee of survival for small construction enterprises.

\section{Conclusions and recommendations}

Improving the marketing activities of small construction companies is a complex and fairly individual process, but there are common features and patterns in this process. The present article is devoted to revealing and taking into account these regularities. The research conducted by the authors shows the extreme instability of small business in the construction industry in Russia. They do not have sufficient resources to compete with large and medium-sized enterprises, they are the first to leave the market or go bankrupt in the years of crises and industrial stagnation.

Therefore, the processes of improving the marketing activities, production and survival of small businesses in complex market conditions are closely related. Analysis of successful small construction enterprises demonstrates the need for deep marketing analysis of the market situation, the active promotion of products and services on the Internet, the introduction of innovative technologies in the production or creation of innovative products, cooperation and integration with large and medium-sized enterprises of the industry, including in the form of virtual enterprises.

\section{References}

1. M.W. Staniewski, R. Nowacki, A. Awruk, K. Int. Entrep. Manag. J. 12, 861 (2016) https://doi.org/10.1007/s11365-016-0385-8

2. A. Tezel, L. Koskela, Z. Aziz, LC3 2017 Volume II - Proceedings of the 25th Annual Conference of the International Group for Lean Construction (IGLC), 853-859 (2017) DOI: https://doi.org/10.24928/2017/0328

3. V. Navickas, A. Malakauskaite, Journal of Business Economics and Management 10-3, 255-259 (2009) https://doi.org/10.3846/1611-1699.2009.10.255-259

4. F.L. Ribeiro, M.T. Fernandes, Journal of Enterprise Information Management 23-2, 161-180 (2010) https://doi.org/10.1108/17410391011019750

5. G. Dragoi, S.M. Rosu, O.-B. Pavaloiu, A. Draghici, Procedia Technology 9, 431 - 441 (2013) 